\title{
Effect of Moringa Oleifera (horseradish) Seed on the Reproductive System of Male Wistar Albino Rats
}

\author{
Eneh Frank Uchenna ${ }^{1}$, Adobeze Linda $\mathbf{N}^{1}$, Adindu Chukwuemeka Steve ${ }^{1}$, \\ Anagonye Callistus O. ${ }^{1}$ \\ ${ }^{1}$ Department of Applied Biochemistry, Nnamdi Azikiwe University, Awka, Nigeria
}

*Corresponding Author: Adindu Chukwuemeka Steve, Department of Applied Biochemistry, Nnamdi Azikiwe University, Awka, Nigeria

\begin{abstract}
The effect of Moringa oleifera seed on the reproductive system of male wister albino rats was studied. Fifteen adult male rats were randomly divided into three groups viz: Test, Control and Baseline. The animals in the baseline group were sacrificed at the onset of the study to determine the initial levels of each andrological parameter. The control group were placed on a compounded diet while the test group received a diet comprising of $1 \% \mathrm{M}$. oleifera seed. Data on body weight, testes weight, sperm count (SC), sperm motility(SM), sperm morphology (SMO), and levels of serum testosterone (TT), luteinizing hormone (LH) and follicle stimulating hormone (FSH) were obtained. The initial and final weights for the test, control and baseline were $124.27 \mathrm{~g}(195.02 \mathrm{~g}), 124.87 \mathrm{~g}(169.93 \mathrm{~g})$ and $124.79 \mathrm{~g}(0.00 \mathrm{~g})$ respectively. The test group showed a significant increase $(P \leq 0.05)$ in body weight as compared to the control and baseline, and also a significant decrease $(P<0.05)$ in sperm count, sperm motility and sperm morphology; $1.60 \times 10^{9} \mathrm{ml}, 10.40 \%$ and $16.40 \%$ when compared to the values obtained for the control and baseline which were $22.60 \times 10^{9} \mathrm{ml}, 62.00 \%, 68.00 \%$ and $18.60 \times 10^{9} \mathrm{ml}, 54.00 \%, 64.00 \%$ respectively. There was no significant decrease $(p>0.05)$ in the testes weight of the test group compared to the control. There was a reduction in the testosterone level of the test group compared to the control and baseline groups though this was not statistically significant $(p \leq 0.05)$ .The reduction in the serum luteinizing hormone level of the test and control groups was not statistically significant ( $p>0.05)$ compared to the baseline group. There was an increase in the FSH level of the test and control groups in relation to the baseline group though this was not statistically significant $(p \geq 0.05)$. It can be concluded that $M$. oleifera seed may have adverse effect on male reproductive system.
\end{abstract}

\section{INTRODUCTION}

\subsection{Background of Study}

Plants have played a significant role in maintaining human health and improving the quality of human life for thousands of years and have served as valuable components of drugs, seasonings, beverages, cosmetics and dyes. Herbal medicine is based on the premise that plants contain natural substances that can promote health and alleviate illness [1]. In recent times, focus on plant research has increased all over the world and a large body of evidence has been collected to show immense potential of medicinal plants used in various traditional system. Today, we are witnessing a great deal of public interest in the use of herbal remedies. Furthermore, many western drugs had their origin in plant extract. There are many herbs which are predominantly used to treat cardiovascular problems, liver disorder, central nervous system disorder, digestive and metabolic disorders. Given their potential to produce significant therapeutic effect, they can be useful as drug or supplement in the treatment or management of various diseases [2]. Herbal drugs or medicinal plants, their extracts and their isolated compounds have demonstrated a wide spectrum of biological activities. Such have been used and continued to be used as medicine in folklore or food supplement for various disorders.

One such plant, Moringa oleifera, invites attention on the researchers worldwide for its pharmacological activities ranging from anti-inflammatory to anti-cancer activities. Moringa oleifera is a rapidly growing tree that is native to the sub-Himalayan tracts of India, endemic in Asia and the most widely cultivated species of a monogeneric family, the moringaceae [3]. This plant is extraordinary because all of its parts are edible and possess nutritional and medicinal values. Moringa oleifera tree has been reportedly shown to have various biological activities such as 
Hypocholesterolemic, antitumor and antihypotentive agents [4], as well as antibiotic and anticancer properties [5]. It is used in the treatment of ascites, rheumatism, venomous bites, cardiac and circulating stimulant [6]. According to [7], the many uses for moringa include: alley cropping (biomass product), animal forage, biogas (from leaves), domestic cleaning agents (crushed leaves), blue dye (wood), fencing (living trees), honey (flower nectar), medicinal (all plant parts). In the west, one of the best known uses for moringa is the use of powdered seed to flocculate contaminants and purify drinking water [8]. Its leaves are an excellent source of vitamin A, B, C, calcium and potassium. Moringa contain specific plant pigments with demonstrated potent antioxidant properties such as carotenoids-lutein, alpha-carotene and $\beta$-carotene, Xanthines and chlorophyll; other phytochemicals with known powerful antioxidant ability-kaempferol, quercetin, rutin and powerful antioxidant, vitamins-C, E and $\mathrm{A}$ and essential micronutrient with antioxidant activity-selenium and zinc. In addition, leaf extract have been shown to regulate thyroid status [9].

The role of the plant in improving male reproductive function has been a focus of interest. This accounts to the fact that male infertility is one of the problems faced by $10 \%$ of couples in the society and within the population, incidence rate of male fertility is approximately 1 out of 36 individuals or $0.76 \%$ based on Himalayan White House International College (HWHIC) India. In the country, a work by the Bureau of plant industry (BPI) showed that a steady diet of moringa fruit boasts the sperm count of men, thus, improving their chances of fertilizing an egg [10]. [11] studied the effects of Moringa oleifera lam on the reproduction of male mice (Mus musculus), using hexane extracts of the leaves. Data of body weights, weights of reproductive organs, diameter of seminiferous tubule, stages of maturity, and level of FSH and LH was analyzed. The significant findings were increased thickness of epidermal wall (at medium and higher doses); higher score for lumen formation (at high dose) and epidermal inactivity (at all doses). No effects on the levels of both hormones. [12] reported an increase in sperm count in male mice when $1 \%$ concentration of moringa ethanolic leaf extract was administered subcutaneously for two weeks. However, the effects of the seed on the hormonal profile of the reproductive organs have not been examined.

The aim of this study was; therefore, to investigate the effect of moringa oleifera seed on the male reproductive system in relation to change in weight of testes, sperm count, sperm motility and sperm morphology using wistar albino rats as test animals. Since spermatogenesis is a hormone dependent phenomenon, the measurement of sperm testosterone, FSH and LH levels were included.

\section{Materials ANd Methods}

\subsection{Sample Collection}

The seed of M. oleifera were purchased from the department of Botany, Nnamdi Azikiwe University, Awka, Anambra State, Nigeria.

M.oleifera whole seeds were dehusked and milled using a mechanical grinding machine (Corona, Lander YCIA, Medellin-Colombia).

Table1. Composition of Experimental Diet for the Control Group (g/100g DIET)

\begin{tabular}{|l|l|l|}
\hline Corn Starch & 59 & \\
\hline Casilan & 26 & \\
\hline Vitamins & & 1 \\
\hline Minerals & & 4 \\
\hline Vegetable oil & 10 & \\
\hline
\end{tabular}

The diet for the test group was constituted by incorporating $1 \mathrm{~g}$ of the milled M. oleifera seed into $99 \mathrm{~g}$ of the control diet (1\% M. oleifera diet)

\subsection{Experimental Animals}

Fifteen adult male wistar rats ( 8 weeks old, $118 \mathrm{~g}-131 \mathrm{~g}$ ), were bought from the Faculty of Veterinary Medicine, University of Nigeria, Nsukka, Enugu state, Nigeria. The animals were acclimatized for seven days during which food and water were given ad libitum, the rats were randomly divided into three groups: Control (PO), Test (MO) and the Baseline of 5rats each. The baseline groups were sacrificed, while the control and test groups' rats were fed with the formulated experimental diets for 31days. The weights of the rats were taken at one week intervals. 


\subsection{Sacrifice and Sample Collection}

At the end of administration, the animals were fasted for $12 \mathrm{hrs}$ and anaesthetized with chloroform. Blood sample $(5 \mathrm{ml})$ was collected by cardiac puncture into EDTA bottle for FSH, testosterone and LH analysis. Then cervical dislocation was carried out. The abdominal cavity was opened up through a mid-line abdominal incision to expose the reproductive organs. The testes were collected, cleared of fat, and weighed using analytical weighing balance, body weights were assessed relative to animal testes weight.

\subsection{Estimation of Sperm Parameters}

As described by [13] ; [14], sperm motility and morphology were determined by removing the cauda part of the epididymis and placing it in a beaker containing $1 \mathrm{ml}$ physiological saline solution after which each section was quickly incised with a pair of sharp scissors and left for a few minutes to liberate its spermatozoa into the saline solution. Semen drops were placed on the slide. The slide was mounted on the microscope and investigated using $\mathrm{x} 40$ objective lens for sperm motility and morphology. Sperm count was done under the microscope by visual counting.

\subsection{Estimation of Serum Levels of the Hormones}

As described by [13], serum testosterone concentration were estimated using enzyme immunology Assay Kits (immunomertrics, London U.K.), according to manufacturer's protocol. Plasma samples were collected and stored at $-20^{\circ} \mathrm{C}$ until assayed. The EIA Kits contain controlled testosterone EIA substrate reagents and EIA quality control samples. A quality sample was run for the hormone at the beginning and at the end of the assay variation. The EIA Kit used had a sensitivity level of $0.3 \mathrm{nmol} / \mathrm{L}$ $(0.1 \mathrm{ng} / \mathrm{ml})$. The intra and inter assay variations were $11.00 \%$ and $10.10 \%$ respectively.

For LH estimation, the EIA Kits contain -Enzyme reagent solution while for FSH estimation, the EIA Kits contain FSH Enzyme reagent solution and EIA quality control samples.

\section{RESULTS}

Table2. The body weight of the treatment groups

\begin{tabular}{|l|l|l|}
\hline Week No. & Control $(\mathbf{g})$ & Test $(\mathbf{g})$ \\
\hline 1 & $124.89 \pm 1.68$ & $124.27 \pm 1.45$ \\
\hline 2 & $134.10 \pm 1.25$ & $133.83 \pm 1.40$ \\
\hline 3 & $141.62 \pm 1.63$ & $149.83 \pm 3.44$ \\
\hline 4 & $151.58 \pm 1.88$ & $163.76 \pm 1.91$ \\
\hline 5 & $162.35 \pm 2.14$ & $183.73 \pm 2.46$ \\
\hline 6 & $169.93 \pm 1.61$ & $195.02 \pm 3.73$ \\
\hline
\end{tabular}

Data presented as mean \pm SEM

Table3. The testes weight of the various treatment groups

\begin{tabular}{|l|l|}
\hline Groups & Testes weight $(\mathbf{g})$ \\
\hline Baseline & $2.02 \pm 0.15$ \\
\hline Control & $2.19 \pm 0.06$ \\
\hline Test & $2.10 \pm 0.06$ \\
\hline
\end{tabular}

Data presented as mean \pm SEM. There was no significant decrease $(p>0.05)$ in the testes weight of the test group compared to the control

Table4. The body weight/testes weight ratio

\begin{tabular}{|l|l|}
\hline Groups & Body weight/Testes weight \\
\hline Baseline & 57.02 \\
\hline Control & 77.59 \\
\hline Test & 92.87 \\
\hline
\end{tabular}

Table5. The serum testosterone levels

\begin{tabular}{|l|l|l|l|}
\hline Groups & Hormone & LH(mIU/ml) \\
\hline & TT(ng/ml) & \multicolumn{1}{|l|}{ FSH(mIU/ml) } & $0.12 \pm 0.02$ \\
\hline Baseline & $4.26 \pm 0.90$ & $0.94 \pm 0.32$ & $0.10 \pm 0.03$ \\
\hline Control & $4.94 \pm 1.70$ & $1.84 \pm 1.44$ & $0.10 \pm 0.03$ \\
\hline Test & $2.04 \pm 1.50$ & $1.76 \pm 1.31$ & \\
\hline
\end{tabular}

Data presented as mean \pm SEM: There was a reduction in the testosterone level of the test group compared to the control and baseline groups though this was not statistically significant $(p \leq 0.05)$ 
Table6. The sperm count, sperm motility and sperm morphology of the treatment groups

\begin{tabular}{|l|l|l|l|}
\hline Groups & $\mathbf{S C}(\times \mathbf{1 0} / \mathbf{m l})$ & $\mathbf{S M}(\boldsymbol{\%})$ & SMO(\%) \\
\hline Baseline & $18.60 \pm 3.48$ & $58.00 \pm 13.93$ & $64.00 \pm 9.27$ \\
\hline Control & $22.60 \pm 2.77$ & $62.00 \pm 12.00$ & $68.00 \pm 8.00$ \\
\hline Test & $14.27 \pm 2.80$ & $10.40 \pm 5.30$ & $16.40 \pm 6.55$ \\
\hline
\end{tabular}

Data presented as mean \pm SEM. There was a significant decrease $(p \leq 0.05)$ in the sperm count, sperm motility and sperm morphology of the test group compared to the control and baseline groups.

\section{DISCUSSION}

There was a significant increase $(\mathrm{P} \leq 0.05)$ in the body weight of rats fed with $M$. oleifera compared to the control. This suggests that Moringa seed enhanced the metabolic processes of the test animals. This result is supported by the findings of [15]; [16], who reported that oral test, acute and chronic toxicity tests on rats with both Moringa stenopetala and M. oleifera seed produced no toxic effects, but rather increased the weights of the rats. The detrimental effect of $M$. oleifera seed on male reproductive system is clearly manifested in all the rats in the test groups compared to the control. The rats fed with Moringa seed showed reduction in reproductive potential when compared to those of the control. Observation of testes weights, levels of serum testosterone hormone, sperm count, sperm motility and sperm morphology constituted supporting evidence. The reduction in the serum luteinizing hormone level of the test and control groups was not statistically significant ( $>0.05)$ compared to the baseline group. There was an increase in the FSH level of the test and control groups in relation to the baseline group though this was not statistically significant $(p \geq 0.05)$. This observation is supported by what was observed by [11], who studied the effects of Moringa oleifera on the reproduction of male mice (Mus musculus), using hexane extracts of the leaves. Data of body weights, weights of reproductive organs, diameter of semineferous tubule, stages of maturity, and level of FSH and LH was analyzed. The significant findings were increased thickness of epidermal wall (at medium and higher doses); higher score for lumen formation (at high dose) and epidermal inactivity (at all doses). However, the rats fed with Moringa seed showed no significant decrease $(p<0.05)$ in the testes weights and level of serum testosterone.

In addition, sperm count, sperm motility and sperm morphology were also used in this study since they are usually evaluated to determine the fertility of a male subject. When critical percentages (i.e. $\geq$ $10 \%)$ of sperm cell abnormally are present in the semen, the male subject is usually considered infertile [17]. The sperm count was observed to have reduced significantly $(\mathrm{p}<0.05)$ in the test group $(1.60 \pm 1.40)$ when compared to that of the control and baseline $(22.60 \pm 2.77$ and $18.60 \pm 3.49)$ respectively, which is an indication that the Moringa seed reduced or inhibited spermatogenesis. This is similar to what was observed in some medicinal plants with detrimental effects on the male fertility such as Carica papaya and Quassia amara. C. papaya was reported by [18] to have anti fertility effect by reduction of sperm count when benzene extract of the seeds was administered to male albino rats. These observations are contrary to what was reported by [12] who reported an increase in sperm count in male mice when $1 \%$ concentration of moringa ethanolic leaf extract was administered subcutaneously for two weeks.

The chloroform extract of the bark of Quassia amara has been shown to decrease sperm count and viability in albino rats [19], while on the contrary, aqueous extracts of root, leaf or whole plant of Withania somnifera Dunai is known to increase sperm count [20]. Also, the sperm motility was also observed to have reduced significantly $(\mathrm{p}<0.05)$ in group A rats $(10.40 \pm 5.30)$ when compared to the control and baseline $(62.00 \pm 12.00$ and $58.00 \pm 13.93)$ respectively which shows that moringa seed affect the live ability of the spermatozoa and caused deformation of the cells and rendered them less motile or immotile. This observation is similar to what was reported by [18] who found Carica papaya to have anti-fertility effect by reduction of sperm motility when benzene extract of the seeds was administered to male albino rats. Also, the chloroform extracts of the bark of Quassia amara has been shown to decrease sperm motility in albino rats [19]. These observations are contrary to what was reported for curcuma longa from the same family cucurbitaceae and Garcinia kola. Curcuma (from rhizome; curcuma longa L.) and kolaviron (a biflavonoid from the seeds of Garcinia Kola) were discovered to prevent peroxidative changes in the sperm membrane, thus enhancing sperm motility and decreasing spermatozoa abnormalities [21]; [22]. 
The degree of sperm morphology (\% Normal) were significantly lower $(\mathrm{p}<0.05$ in the test group

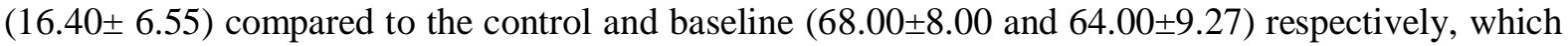
is an indication that the Moringa seed caused morphological alterations of sperm cells probably by interfering with maturation stage of spermatogenesis in the seminiferous tubule.

\section{CONCLUSION}

Findings from this study shows that Moringa seed caused increased sperm cell abnormalities. The sperm cell abnormalities tended toward critically high percentage occurrence. This indicates that prolonged feeding on $M$. oleifera seed could compromise fertility in males. Herbal application of Moringa seed should therefore be taken with caution in both man and animals, especially in male animals used in breeding programs. The potential of the plants as an anti-fertility drug in man could be carefully explored. In consideration of other health benefits of Moringa oleifera, it is suggested that appropriate processing methods should be adopted on $M$. oleifera seeds to reduce or eliminate the anti-fertility components or contraindications thereby making it a more acceptable food product.

\section{REFERENCES}

Gupta, A.K. and Mishra, S.K. (2002). Indigenous phytoterapy for diabetes from chtlisgara. Advanced Plant Sci. 15(2):407-409.

Benneth, R.N., Mellon, F.A., Foildl, N., Pratt, J.H., Dupont, M.S., Perkins, L., Kroon, P.A., (2004). Profilling glucosinolates andphenolics in vegetative and reproductive tissues of the multipurpose trees of Moringa oleifera and Moringa stenopetala L., Journal of Agricultural and Food Chemistry. 51(12): 546-3553.

Fahey, H., (2000). Moringa oleifera: A Review of the medical Evidence for its Nutritional. Therapeutic and prophylactic properties. Part1. Trees of Life J., 2005, 1:5.

Richa, P., Yardleg, V. and Rock, P. (2005). Hypocholesterolemic effects of fruits of moringa. . Indian J. Nat. Prod.. 13:3-10.

Paul, C.W. and Didia, B.C. (2012). Methanolic extract of Moringa oleifera lam root is not test friendly to Guinea pigs. Asia Journal of Medinal Sciences. 4(1):47-54.

Lilipun, V.M., Kurokawa, R., Suttisri, P., Taweechotiparr, P., Pramyothin, M., Hatori, K. and Shiraki, A. (2003), "Efficacy of Thai medicinal plant extracts against herpes simplex virus type 1 infection invitro and in vivo". Antiviral Research, 60, 175-180.

Fugile, L.J., (2001). The Miracle tree: Moringa oleifera Natural Nutrition for the tropics. The multi attributes of Moringa, 172pp.

Berger, M.R., Habo, M., John, S.A., Schmahl, S., (2005). Toxicological assessment of seeds from Moringa oleifera and Moringa stenopetala, two highly efficient primary coagulant for domestic water treatment of tropical raw water. East African Journal 61:712-716.

Tahiliani, Pol., Kar, A. (2000). Role of Moinga oleifera leaf Extract in the regulation of thyroid hormone status in adult male and female rats. Pharmacol. Res. 41:319-323.

Cabacungan (2008). Inquirer.net, Legarda pushes for malunggay, herbeauty soup.

Lilibeth, A.C. and Glorina, L.P. (2010). Effects of Moringa Lam. (Moringaceae) on the reproduction of male mice (Mus musculus). Journal of medicinal plants research 4(12):1115-1121.

Serrano Pocsidio (2008). Effects of Moringa oleifera lam leaf Extracts on Reproductive Organ, morphology and sperm parameters in male mice. Unpub.

Saalu, L.C., Togun, V.A., Oyewopo, A.O., Raji, Y.,(2006). Artificial Cryptorchidisn and the Moderating effect of melatonin in sprague- Dawley rats. J. Appl. Sci. 6(14): 2889-94.

Saalu, L.C., Adesanya, A.O., Oyewopo, A.O., Raji, Y., (2007). An evaluation of the deleterious effect of unilateral cryptorchidism on the contralateral normally descended testis. Sci. Res. Essays 7(4):74-8.

Sattaur, O. (1983). The light of the village. New Scientist, 100: 830-831.

Jahn, S. A. A. (1988). Using Moringa seeds as coagulants in developing countries. J. Am. Water Works Assoc. 80: 45-50.

Zemjanis, R. (1977) Collection and evaluation of semen. In: Diagnostic and therapeutic techniques in animal reproduction. William and Wilkins Company, Baltimore, USA. P.242. 
Chinoy, N. J. and Padman, P. (1996) Antifertility investigation on the benzene extract of carica papaya seeds in male albino rats. J. Med. Aromatic plant science. 19(2):422-426.

Parveen, S., Das, S., Kundra, C.P., Pereira, B.M., (2003). A comprehensive evaluation of the reproductive toxic of Quassia amara in male rats. Reprod. Toxical 17(1): 45-50.

Abdel - Magnied, E.M., Abdel-Rahman, H.A., Hanaz, F.M. (2001). The effect of Aqueous extracts of cynomorium coccineum and withania somnifera on testicular development in inmature wistar rats. J. Ethnopharmacol. 75:1-4.

Farombi, E.O., Abarikwu, S.O., Adedara, I.A., Onyeyemi, M.O., (2007). Curcumin and Kaloviron ameliorate di-n-Butylphthalate-induced testicular damage in rats. Basic clin. Pharmacol. Toxicol. 100:43-48.

Ishihara, M., Itoh, M., Miyamoto, K., Takeuchi, Y., Takenaka, I., Jitsunari, F. (2000). Spermatogenic disturbance induced di-(2-ethylhexyl) phlthalate is significantly prevented by treatment without anti oxidant vitamins in rats. Int. J. Androl, 23;85-94.

Citation: E. Uchenna, "Effect of Moringa Oleifera (horseradish) Seed on the Reproductive System of Male Wistar Albino Rats", International Journal of Research Studies in Biosciences (IJRSB), vol. 5, no. 9, pp. 22-27, 2017. http://dx.doi.org/10.20431/2349-0365.0509005

Copyright: (C) 2017 Authors. This is an open-access article distributed under the terms of the Creative Commons Attribution License, which permits unrestricted use, distribution, and reproduction in any medium, provided the original author and source are credited. 